\title{
Development of a Self-Report Inventory for Assessing Individual Differences in Learning Processes
}

\author{
Ronald Ray Schmeck, Fred Ribich, and Nerella Ramanaiah \\ Southern Illinois University
}

Five studies are presented-all related to the development and application of a self-report inventory for measuring individual differences in learning processes. Factor analysis of items derived by translating laboratory learning processes into the context of academic study yielded four scales: Synthesis-

Analysis, Study Methods, Fact Retention, and Elaborative Processing. There were no sex differences, and the scales demonstrated acceptable reliabilities. The Synthesis-Analysis and Elaborative Processing scales both assess aspects of information processing (including depth of processing), but SynthesisAnalysis assesses organizational processes, while Elaborative Processing deals with active, elaborative approaches to encoding. These two scales were positively related to performance under incidental learning instructions in both a lecture-learning and traditional verbal-learning study. Study Methods assessed adherence to systematic, traditional study techniques. This scale was positively related to performance in the intentional condition of the verbal learning study. The Fact Retention scale assessed the propensity to retain detailed, factual information. It was positively related to performance in the incidental condition of the verbal-learning but not the lecture-learning study. Future research and applications are discussed.

Recently, several researchers in the area of human learning and memory have emphasized the importance of processes such as encoding

\footnotetext{
APPLIED PSYCHOLOGICAL MEASUREMENT

Vol. 1. No. 3 Summer 1977 pp. 413-431

(C) Copyright 1977 West Publishing Co.
}

(Melton \& Martin, 1972), organization (Tulving $\&$ Donaldson, 1972), imagery (Paivio, 1971), and depth of processing (Craik \& Tulving, 1975). The present paper describes the development of an instrument for measuring individual differences in such learning processes.

Since Cronbach's (1957) plea for research combining correlational and experimental approaches, there has been a growing interest in the study of individual differences in learning (e.g., Gagné, 1967). Much of this research has been done in the applied areas of teaching and counseling. With the exception of a few studies (e.g., Biggs, 1970; Goldman \& Warren, 1973), many of the applied studies have mainly employed personality, attitudinal, and cognitive style measures (e.g., Cowell \& Entwistle, 1971; Cropley \& Field, 1969). After reviewing the research in this area, Tallmadge and Shearer $(1969,1971)$ have concluded that learning style assessed from a behavioral-process orientation is more likely to be useful than one based purely on a personality- or cognitive-style orientation.

In laboratory research, experimenters have frequently employed performance measures of individual differences. For example, in order to study individual differences in organizational processes, Earhard (1974) and Thompson, Hamlin, and Roenker (1972) essentially ran subjects once to establish individual differences and then ran them again in the same or similar laboratory 
situation to determine the impact of the individual differences on further learning. Unfortunately, such measures are time-consuming and laborious, and they may be subject to the influence of common method variance, since the measure of individual differences and the experimental measures are based on the same method of measurement.

Following the recommendation of Tallmadge and Shearer (1969, 1971), the present authors developed a self-report inventory using behaviorally oriented statements to assess important learning processes in the academic setting. The primary goal in the preparation of the item pool was to represent the findings and theoretical processes of information processing, especially as they have been applied to the verbal and prose learning areas. Essentially, the authors consulted advanced information-processing and verbal- and prose-learning texts in order to list the major processes which have been uncovered by research or advocated by various theoretical points of view. Each of the authors then attempted to write items to assess these processes by phrasing behavioral descriptions in terms of the environment and activities of the typical college student. In addition, the authors prepared a variety of items which were related to academic activities but which had no obvious preconceived relationship to any established learning processes. These items were included in the hope that some of them would cluster with the information-processing items or form separate clusters revealing unanticipated learning processes. These latter items were concerned with behaviors which students engage in while attending lectures and films, taking notes, writing papers, making plans, interacting with other students, and generally preparing for academic examinations.

In order to illustrate how the item pool was developed, it will be useful to consider a few of the well-known processes which served as starting points and present some sample items suggested by these processes. Basic to the information processing area are the concepts of encoding, storage, and retrieval. The concept of en- coding has been studied extensively in the area of verbal learning and memory (e.g., Melton \& Martin, 1972). Encoding refers to the process whereby the learner transforms new information into a form which can more readily be related to the old information which is already stored in memory. Relevant inventory items may take the form: "I learn new words and ideas by associating them with words and ideas which I already know"; or "I learn new ideas by relating them to similar ideas." Storage refers to the holding of information in memory and could be measured by inventory items such as: "I memorize material as given in the text"; "my memory is actually pretty poor"; and "I have trouble remembering definitions." Retrieval refers to the process whereby information is brought forth from memory, and Eysenck (1974) provides evidence of individual differences in information retrieval. Inventory items related to retrieval might take the form, "When I study something, I devise a system for recalling it later."

Another information-processing variable, which has been stressed in recent verbal-learning and memory studies, concerns the changes in the organization of information which occur between the time it is originally presented to a subject and the time that he/she is asked to recall it (Tulvig \& Donaldson, 1972). Such organizational processes clearly improve recall. In verbal learning the terms clustering (e.g, Bousfield \& Bousfield, 1966) and subjective organization (e.g., Tulving, 1962) refer to systematic changes in word order which occur between the time when the subject studies a list of words and the time when his/her recall is tested. In this context, Earhard (1974) and Thompson, Hamlin, and Roenker (1972) reported that there are individual differences in the tendency to organize word lists and that such differences are related to amount and content of recall. Similar organizational processes have been studied in relation to textbook and lecture learning (e.g., Frase, 1969; Shultz \& DiVesta, 1972). Inventory items concerned with organizational processes might take the form, "I have trouble organizing 
the information that I remember" or "I generally prepare a set of notes integrating the information from all sources in a course."

Another aspect of information processing might be referred to as elaborative processing. There are several ways in which an individual can elaborate upon given information. One involves the use of imagery, i.e., visually imaging situations which exemplify the given information. Paivio (1971) reports substantial improvement in memory produced by the use of imagery. He has also reported some successful attempts to measure individual differences in the use of imagery. This process suggests inventory items such as: "I learn new words and ideas by visualizing a situation in which they occur." Elaborative methods of processing information also involve the depth to which information is processed. Craik and Tulving (1975) suggest that information processing can vary along a continuum from "shallow," involving attention to superficial aspects of the material, to "deep," in which the learner delves into the subtle nuances, meaning, and personal relevance of new information by thinking about it. In the verbal-learning area, it has been found that "deeper" processing improves recall (Craik \& Tulving, 1975). Similar findings have been obtained in regard to textbook learning(e.g., Anderson and Kulhavy, 1972). Inventory items related to shallow processing might take the form, "I often memorize material that I don't understand." At a deeper level, we might have: "I learn new ideas by expressing them in my own words" or "While learning new concepts, their practical applications often come to mind."

This paper presents five separate studies concerned with the development of a self-report inventory of learning processes. The first study reports the actual development of scales assessing various learning processes. Since some of the items in the scales developed in the first study had to be reversed in order to balance the number of true-keyed and false-keyed items, the second study tested the effect of item reversals on the stability of the item responses. The next study was concerned with sex differences, inter- correlations, internal consistency, and test-retest reliability of the various scales. The last two studies were designed to provide preliminary indications of the validity of the scales. One study examined the relationships between the scales and performance on an unannounced objective examination in a lecture-learning setting. The final study examined similar relationships using a standard laboratory verbal learning paradigm. In addition, this study attempted to assess the relative independence of the learning process scales as compared with selected measures of personality and cognitive style.

\section{SCALE DEVELOPMENT}

\section{Study 1}

The aim of the first study was to identify clusters of items which could be used to develop scales with adequate reliability. Responses to the initial item pool were factor analyzed and, as recommended by Berdie and Campbell (1968) and Wang and Stanley (1970), scales and scoring keys were constructed by giving unit weight to the salient items.

\section{Method}

Subjects. The subjects were 503 undergraduate students at Southern Illinois University. The sample was composed of 237 males and 266 females, with 87 freshmen, 199 sophomores, 142 juniors, and 75 seniors representing various academic majors. Participation in the study was voluntary.

Procedure. The preliminary form of the inventory consisted of 121 true-false items describing learning behaviors which might be utilized within an academic setting. The students were instructed to respond to the statements (on standard IBM answer sheets) by considering the manner in which they "generally" learn rather than how they learn within any particular course or academic discipline.

In general, the analysis followed the guidelines recently suggested for questionnaire development by Cattell (1974) and Vaughan 


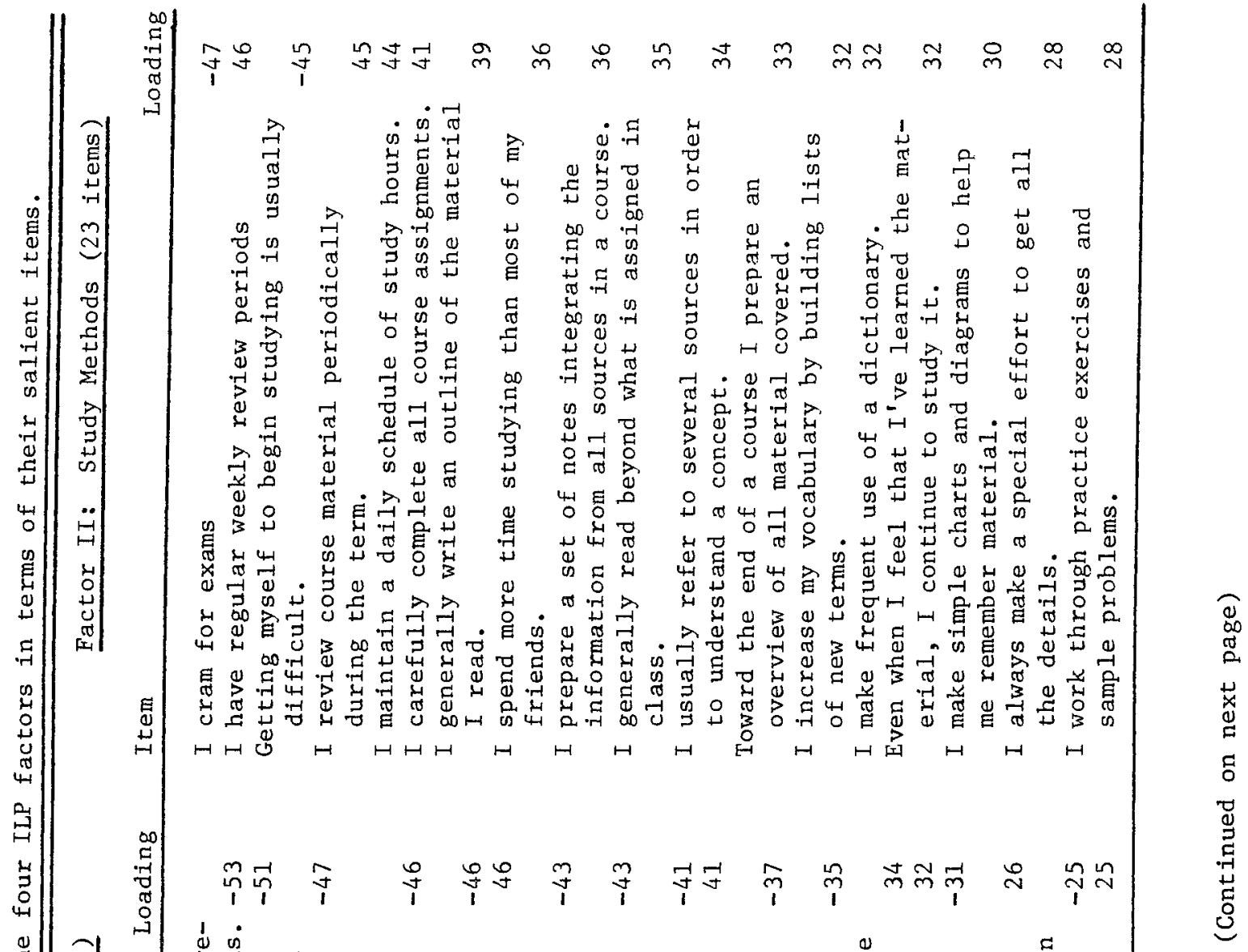

焉

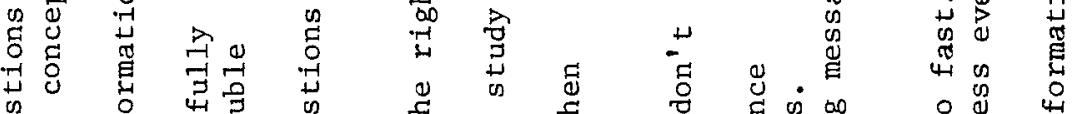

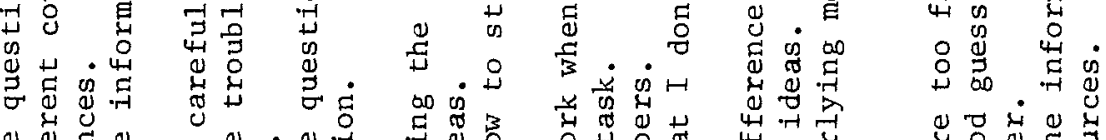

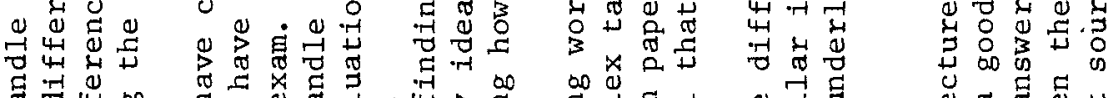

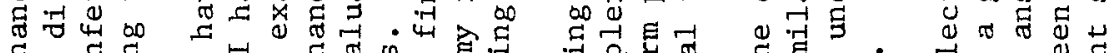

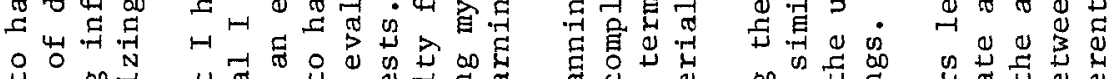

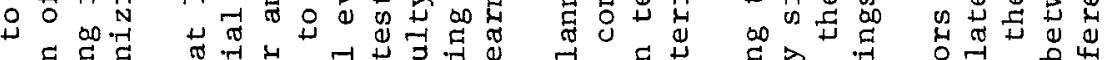

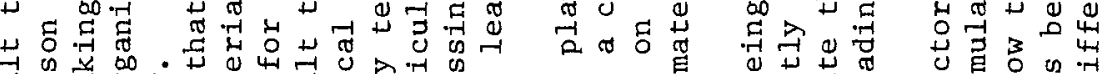

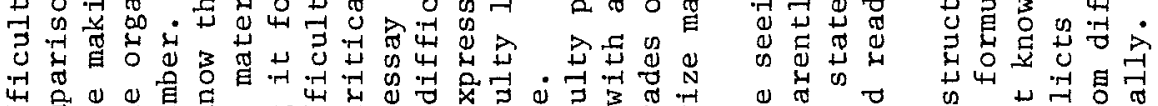

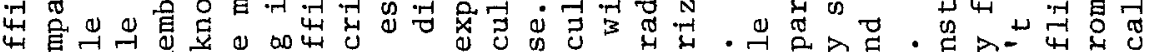

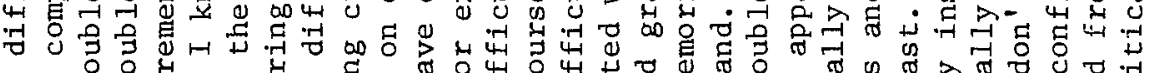
山

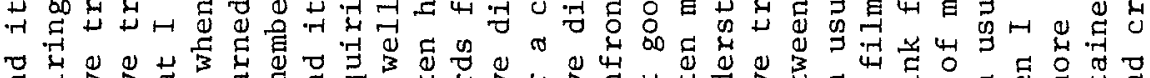

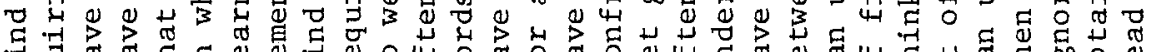

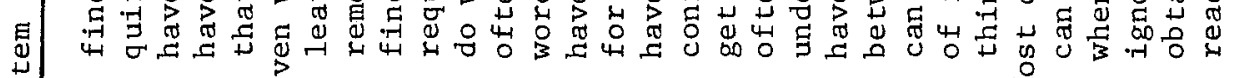




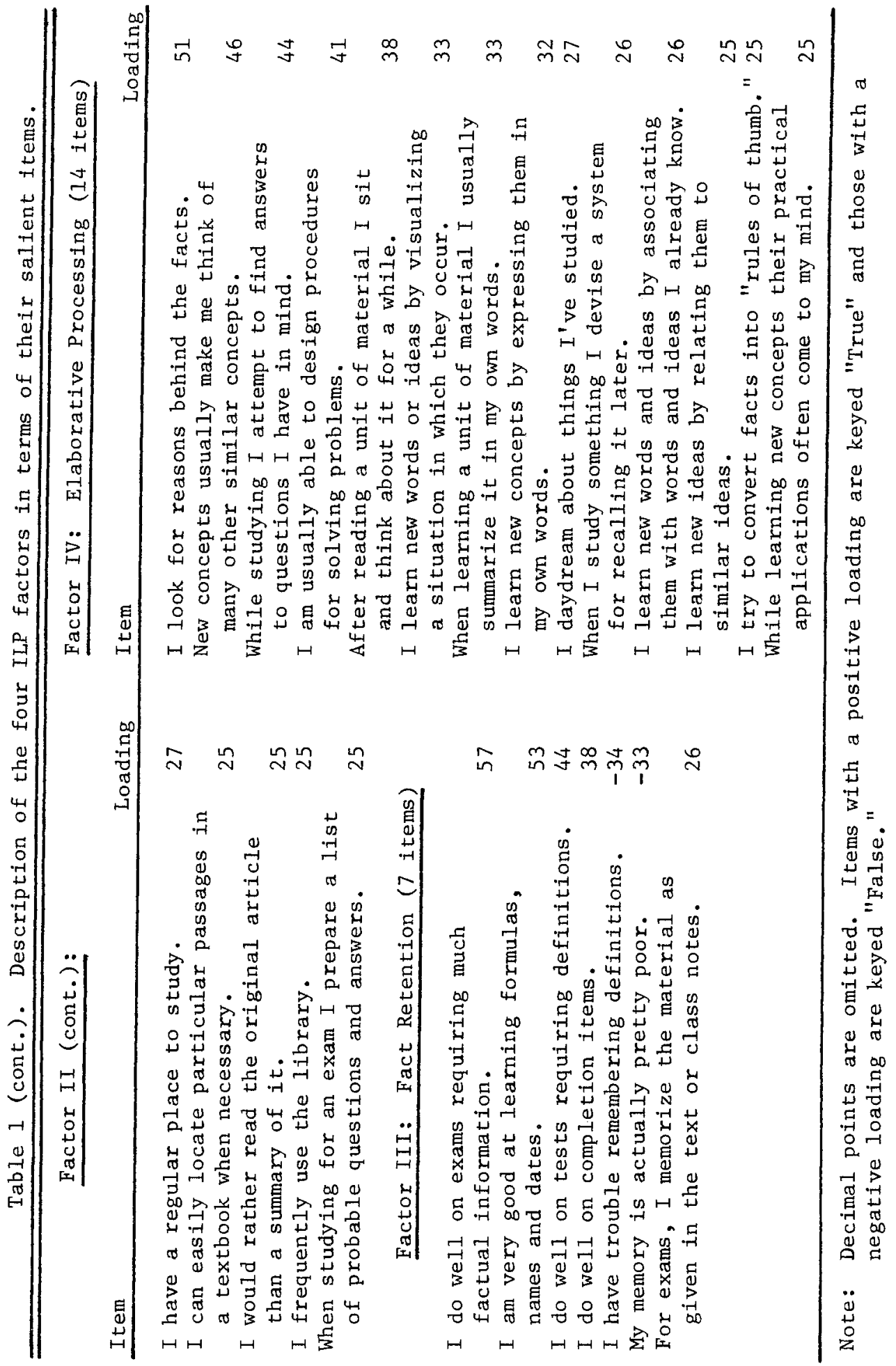


(1973). Intercorrelations among 121 items based on the responses of the 503 students were first subjected to a principal components solution, and a scree test (Cattell, 1966) was used to determine the number of factors. The correlation matrix was then factor analyzed using the principal factor method with squared multiple correlations as estimates of communalities, and the previously determined number of factors were rotated to the Varimax criterion (Kaiser, 1958). Since individual scale reliabilities depend upon the number of items within a scale, only those factors were retained which had five or more items with loadings exceeding .25 and having minimal overlap with other factors.

\section{Results and Discussion}

Although the scree test yielded 15 factors, inspection of the rotated factor matrix indicated that only four of them met the criteria for retention. The four factors encompassed 62 of the original 121 items. Table 1 presents the results of this analysis, giving the items which comprise each factor and their loading on that factor.

Factor $I$ is marked by items which stress evaluation, organization, discrimination, and extrapolation and is referred to as the SynthesisAnalysis factor. Factor II represents the ubiquitous study methods dimension of learning indicating the use of systematic, traditional study techniques. It will henceforth be labeled the Study Methods factor. Factor III, which is called Fact Retention, has substantial loadings for items indicating a preference for factual information and retention of details. Factor IV is comprised of items which stress visualizing, summarizing, relating, encoding, and applying information; it is called the Elaborative Processing factor.

\section{Study 2}

An inspection of the scoring keys for each of the four scales revealed that within each scale there was an imbalance of true-keyed and falsekeyed items. Thus, in order to reduce the influence of response set, several items were selected within each scale which could be conveniently reworded in the reverse direction. A total of 17 items was selected in this fashion, and Study 2 was designed to determine the effect of item reversal on students' responses to the inventory by examining item-stability coefficients (Rorer \& Goldberg, 1965).

\section{Method}

The effect of item reversals was studied by comparing the stability of the responses of students who first responded to the original item and then responded to the reversed item with the stability of the responses of students who twice responded to the original item. An experimental group of students $(N=95)$ completed the original version of the inventory. This was followed two weeks later by the form containing the 17 reversed items. A control group $(N=120)$ filled out the original version of the inventory twice over the same time period. The reversed items are presented in Table 2.

Following Rorer and Goldberg (1965), stability coefficients were computed for the items that were reversed and those that were not reversed. Stability coefficients indicate the percentage of subjects who respond consistently to a particular item on two different occasions. In the case of the control group, stability was defined as the number of subjects who responded "true" on both the first and second administration plus the number of responding "false" on both occasions, divided by the sample size $(N=120)$. In the case of the experimental group, stability for nonreversed items was computed in the same manner as the control group. But, the stability of reversed items for this group was defined as the number of subjects who respond "true" to the given item on the first occasion and "false" on the second, plus the number who respond "false" on the first and "true" on the second, divided by the sample size $(N=95)$. The control group's mean item-stability coefficient for reversed items was compared to that of the experimental group. A similar comparison was made for nonreversed items. 
Table 2. Reversed wording of items incorporated in the final form of the ILP.

Factor I: Synthesis-Analysis

I can easily handle questions requiring comparison of different concepts.

I try to resolve conflicts between the information obtained from different sources.

Factor II: Study Methods

I rarely write an outline of the material I read.

I spend less time studying than most of my friends.

I rarely read beyond what is assigned in class.

I rarely use a dictionary.

I do not usually work through practice exercises and sample problems.

I have difficulty locating particular passages in a textbook when necessary.

I would rather read a summary of an article than the original article.

I rarely use the library.

\section{Factor III: Fact Retention}

I do poorly on completion items.

Factor IV: Elaborative Processing

I rarely look for reasons behind the facts.

New concepts rarely make me think of many other similar concepts.

I am rarely able to design procedures for solving problems.

I rarely sit and think about a unit of material which I have just read.

I do not try to convert facts into "rules of thumb."

While learning new concepts, their practical applications don't usually come to my mind.

\section{Results and Discussion}

For the experimental group which responded first to the original item and then to its reversed form, the mean and standard deviation of the stability coefficients for the 17 reversed items were 72.6 and 6.4 (values ranging from 63.2 to $82.9)$, respectively. The mean and standard deviation of the stability coefficients for the control group which twice responded to the 17 items in their original form were 78.1 and 4.6 (values ranging from 69.2 to 84.1 ). Since there was no significant difference between the mean stability coefficients of the experimental and control groups, it was concluded that the reversal of the 17 items had not altered their original meaning. It may also be noted that the mean and standard deviation of the stability coefficients for the nonreversed items were 78.9 and 5.9 for the control group and 79.2 and 6.4 for the experimental group. The 62-item inventory administered to the experimental group, including the 17 reworded items shown in Table 2 , is hereinafter referred to as the Inventory of Learning Processes (ILP). 
Table 3. Means and standard deviations of the four ILP scales for male and female samples.

\begin{tabular}{|c|c|c|c|c|c|}
\hline & $\mathrm{n}$ & $\begin{array}{l}\text { Synthesis- } \\
\text { Analysis }\end{array}$ & $\begin{array}{l}\text { Study } \\
\text { Me thods }\end{array}$ & $\begin{array}{c}\text { Fact } \\
\text { Retention }\end{array}$ & $\begin{array}{l}\text { Elaborative } \\
\text { Processing }\end{array}$ \\
\hline Males & 232 & & & & \\
\hline Mean & & 11.8 & 10.3 & 4.7 & 10.2 \\
\hline SD & & 4.2 & 4.4 & 1.8 & 2.8 \\
\hline Females & 202 & & & & \\
\hline Mean & & 11.4 & 10.6 & 4.8 & 10.1 \\
\hline SD & & 4.3 & 4.3 & 1.7 & 2.6 \\
\hline
\end{tabular}

\section{Study 3}

The third study was aimed at investigating sex differences, internal consistency and test-retest reliabilities, as well as scale intercorrelations for the final form of the $I L P$. The first step involved the examination of sex differences in terms of individual scales and average profiles. Next, the intercorrelations of the four scales were determined. The subsequent determination of reliabilities involved the calculation of both internal consistency and temporal stability. In order to determine temporal stability, a subsample of students was retested following a two-week interval.

\section{Method}

The final form of the $I L P$ was administered to 434 volunteer undergraduate students $(232$ males and 202 females) from a number of different academic majors, including freshmen through seniors. For estimating test-retest reliability, a subsample of 100 students was asked to return two weeks later for another testing session; 95 of the 100 returned for this session in which the $I L P$ was re-administered. Multivariate analysis of variance was used for testing profile differences between males and females, while univariate $F$-tests were used at the individual scale level.

\section{Results and Discussion}

Table 3 presents the means and standard deviations of males and females on the four $I L P$ scales. Multivariate analysis of variance revealed no significant sex differences for the average profiles. Univariate analysis indicated no significant differences at the individual scale level. Hence, the data for males and females were combined for subsequent analyses. Scale intercorrelations are presented in Table 4 , where it can be seen that the scales are relatively independent. Internal consistencies $(K R-21)$ are also reported on the diagonal in Table 4 . The test-retest reliabilities are also presented in the last column of Table 4. These internal-consistency and test-retest reliability values are in the acceptable range, and the remaining studies reported below are concerned with the application of the $I L P$ within the research setting.

\section{EXPERIMENTAL VALIDATION STUDIES}

\section{Study 4}

This study investigated the relationship between $I L P$ scales and performance in a lecturelearning setting, using a single videotaped lecture followed by an objective examination. Since Plenderleith and Postman (1957) have suggested that individual differences emerge more strongly in incidental (unintentional) learning, the exa- 
Table 4. Intercorrelations, internal consistency, and test-retest reliabilities of the four ILP scales.

\begin{tabular}{|c|c|c|c|c|c|}
\hline & $\begin{array}{l}\text { Synthesis- } \\
\text { Analysis }\end{array}$ & $\begin{array}{l}\text { Study } \\
\text { Methods }\end{array}$ & $\begin{array}{c}\text { Fact } \\
\text { Retention }\end{array}$ & $\begin{array}{l}\text { Elaborative } \\
\text { Processing }\end{array}$ & $\begin{array}{l}\text { Test-Retest } \\
\text { Reliability }\end{array}$ \\
\hline \multicolumn{6}{|l|}{ Synthesis- } \\
\hline Analysis & $(82)$ & & & & 88 \\
\hline Study & & & & & \\
\hline Methods & 26 & (74) & & & 83 \\
\hline \multicolumn{6}{|l|}{ Fact } \\
\hline Retention & 39 & 20 & $(58)$ & & 79 \\
\hline \multicolumn{6}{|l|}{ Elaborative } \\
\hline Processing & 45 & 44 & 13 & $(67)$ & 80 \\
\hline
\end{tabular}

Note: Intercorrelations and internal consistencies were based on a sample of 434 subjects, and test-retest reliabilities were based on a sample of 95. Internal consistencies are listed on the diagonal. Decimal points have been omitted.

mination in the present study was unannounced. In addition, in order to investigate the degree to which the Synthesis-Analysis and Elaborative Processing scales of the $I L P$ deal with high-level cognitive skills, half of the examination was composed of comprehension (high-level) questions and half was composed of knowledge (lowlevel) questions written according to the guidelines of Bloom's (1956) taxonomy.

Since the incidental learning situation precludes study behavior, it was hypothesized that there would be no relationship between the Study Methods scale and performance on the examination. On the other hand, if the Synthesis-Analysis and Elaborative Processing scales assess the "depth" to which subjects habitually process information, then according to Craik and Tulving's (1975) "levels of processing" notion, scores on these scales should be related to examination performance. Furthermore, if synthesis-analysis and elaborative processing require high-level cognitive skills, then individuals who score high on these two scales should also be more proficient at answering high-level cognitive examination questions. Thus, it was hy- pothesized that the Synthesis-Analysis and Elaborative Processing scales would be positively related to both the comprehension and knowledge examination subscores, but the correlation would be greater with the comprehension subscore than with the knowledge subscore.

\section{Method}

The subjects were 32 undergraduate volunteers from an introductory psychology course. Subjects were run as a group and observed a 20minute videotaped lecture on the principles of instrumental conditioning under instructions to list the concepts covered by the lecturer. To provide a rationale for the task, subjects were told that the tape was being screened before being aired to the public, in order to be certain that it did not contain too much information. The videotaped presentation was in color and contained numerous diagrams and illustrations of the principles covered. After watching the videotape, subjects were administered an unannounced 30-item, multiple-choice test composed of 15 items written according to Bloom's (1956) 
guidelines to assess low-level cognitive activity (knowledge) and 15 items written to assess high-level cognitive activity (comprehension). Scoring of the objective test yielded a total score and two subscores-one of knowledge and one for comprehension questions. Following the test, all subjects were administered the $I L P$.

\section{Results and Discussion}

The four learning process scales were correlated with the three objective test scores and the results are presented in Table 5. As expected, there was no significant correlation between the Study Methods scale and examination performance. Also, the results indicate that the total objective test score was significantly related to both the Synthesis-Analysis and the Elaborative Processing scales. This supports the hypothesis that individuals who score high on these two scales habitually process information in depth and thus, in accordance with Craik and Tulving's (1975) notion, retain more of the information, even when they are not advised of an upcoming examination.

The means and standard deviations for the two subtests were 5.0 and 2.0 for the knowledge items and 4.3 and 1.7 for the comprehension items. Although the correlations between the Synthesis-Analysis and Elaborative Processing scales and the comprehension subscores are slightly higher than those for the knowledge subscore (as seen in Table 5), the difference between the correlation coefficients is not significant. It should be noted, however, that the correlation between the comprehension and knowledge subscores themselves was .46. Thus, the absence of a significant differential correlation with the two $I L P$ scales may be accounted for by the method variance shared by the questions entering into the two subscores as well as the fact that knowledge acquisition is a prerequisite to answering comprehension questions. Further research employing independent assessments of knowledge and comprehension levels of learning will be necessary to establish whether the SynthesisAnalysis and Elaborative Processing scales do indeed assess high-level cognitive activities, which bring about more than knowledge acquisition.

\section{Study 5}

The previous study indicated significant relationships between the Synthesis-Analysis and

Table 5. Correlations of the four ILP scales with scores on an objective examination given under incidental learning conditions $(n=32)$.

\begin{tabular}{lccc}
\hline & Knowledge & Comprehension & Total \\
\hline $\begin{array}{c}\text { Synthesis- } \\
\text { Analysis }\end{array}$ & 32 & $40 *$ & $42 *$ \\
$\begin{array}{c}\text { Study } \\
\text { Methods } \\
\text { Fact } \\
\text { Retention }\end{array}$ & 13 & 10 & 13 \\
$\begin{array}{c}\text { Elaborative } \\
\text { Processing }\end{array}$ & 03 & -15 & -07 \\
\hline
\end{tabular}

Note: Decimal points have been omitted.

$*_{\mathrm{p}}<.05$

$* * \mathrm{p}<.01$ 
Elaborative Processing scales and the test performance within an incidental learning situation. The present study investigated learning under both incidental and intentional learning instructions, in order to look for differential relationships between the $I L P$ scales and learning under the two conditions. In addition, the learning task employed in this last study was more typical of laboratory research, involving the presentation of a list of words followed by retention tests.

Since subjects under conditions of intentional learning are specifically instructed to study and retain the words, a positive relationship between retention and the $I L P$ scales of study methods and fact retention was expected. However, since instructions to learn might cause study habits and memorization styles to take precedence over the more subtle information processing strategies of synthesis-analysis and elaborative processing, the authors anticipated that the two latter $I L P$ scales would not be related to retention in the intentional condition. This analysis is supported by Craik and Tulving (1975), who report that incidental learning subjects who are instructed to engage in activities which require that information be processed in depth often perform as well as, or better than, subjects in intentional conditions who are simply instructed to learn. This is taken to be an indication that the study strategies aroused by instructions to learn in the intentional condition may actually be less effective than the deep processing produced by appropriate instructions in the incidental condition.

As in the previous study, a positive relationship between word-list retention and the $S y n$ thesis-Analysis and Elaborative Processing scales should be evident in the incidental condition if these scales do, in fact, assess deep processing strategies which are not specific to the learning task. The Study Methods and Fact Retention scales should be unrelated to learning in the incidental condition, since studying and active attempts at retention are not required.

Recently, researchers (e.g., Paivio \& Csapo, 1973) have shown that memory for imageable material (e.g., pictures, concrete words) is better than that for nonimageable material (e.g., abstract words). In order to investigate whether there are differential relationships between individual difference measures and retention of these two types of material, the word list used in the present study was comprised of half concrete and half abstract nouns. It was expected that the two scales which relate to the organization and encoding of information (i.e., Synthesis-Analysis and Elaborative Processing) would bear a stronger relationship to retention of concrete words as opposed to abstract words.

Traditionally, the two measures of retention of verbal-learning research (i.e, recall and recognition) are assumed to reflect different theoretical processes. Both measures are assumed to reflect storage processes, but recall measures are assumed to reflect search and retrieval processes as well. Consequently, the present study included both measures in order to provide an opportunity to observe differential relationships with the $I L P$ scales. For example, if the $I L P$ scales demonstrate relationships with the recall measures while demonstrating no relationships with the recognition measures, it could be taken as an indication that the scales are mainly tapping search and retrieval processes.

In order to investigate whether the $I L P$ scales are relatively independent of personality and cognitive-style measures, one personality and two cognitive-style measures were also administered in the present study. Recent research which has demonstrated superior learning by extroverted subjects (Eysenck, 1976) served as the rationale for including the Pittsburg Social Extraversion-Introversion Scale (Bendig, 1962). A recent proposal by Schwartz (1975) that field-independent subjects rely more heavily upon internal organizing schema prompted the inclusion of the Hidden Figures Test (French, Ekstrom, \& Price, 1963), with the expectation that it may positively correlate with the ILP SynthesisAnalysis and Elaborative Processing scales. As a second cognitive style measure, the Category Width Scale (Pettigrew, 1958) was also included, since it has been suggested (Schwartz, 1975) that 
narrow categories focus on details and might therefore score high on the ILP Fact Retention scale.

\section{Method}

Materials. Social Extraversion-Introversion Scale (SEIS): This scale, developed by Bendig (1962), consists of 30 true-false, self-report items; high scores indicate social extraversion. Bendig reports high internal consistency; no estimates of test-retest reliability were available.

Hidden Figures Test (HFT): The HFT was the standard version supplied by the Educational Testing Service, (French, Ekstrom \& Price, 1963). It consists of 32 items -16 complex designs presented in each of two 10-minute (timed) halves. In each of the complex patterns, subjects are to locate one of five possible geometric designs. The test was administered using the standard procedure. The individual scores were comprised of the number of figures correctly identified minus one-fourth the number misidentified (to correct for guessing). A high score is indicative of field independence. Internal consistency and test-retest reliabilities are reported to be in the acceptable range (Boersma, 1968).

Category Width Scale (CWS): This scale consists of 40 multiple-choice items which ask subjects to estimate the extremes of a number of diverse categories, from the length of whales to annual rainfall in Washington. The response alternatives are weighted according to category breadth such that high scores indicate broad category width. High scorers have been characterized as having broad equivalence ranges and being risk-takers (Pettigrew, 1958).

The word list for the verbal-learning task consisted of 15 concrete and 15 abstract nouns chosen from those published by Paivio, Yuille, and Madigan (1968). These 30 words were taperecorded in random order at the rate of one word spoken every 3.5 seconds. A recognition test for the word list was constructed by listing on a sheet of paper, in random order, the 30 original nouns and 30 new distractor nouns-the latter being another set of $15 \mathrm{ab}$ stract and 15 concrete words. The ILP was also administered (in the form described elsewhere in the present paper).

Subjects and procedure. The subjects were 62 undergraduate students enrolled in an introductory psychology course at Southern Illinois University; they received additional course credit for participation. The study was conducted in two sessions. In the first, all subjects were administered the $I L P, S E I S, C W S$, and $H F T$ in that order. During the second session, one week later, subjects were randomly assigned to either an intentional or incidental learning condition, depending upon the instruction sheet they received. Due to a clerical error, 32 subjects were assigned to the incidental group while 30 were in the intentional condition.

The incidental orienting task employed in the present study was typical of those used by Craik and Tulving (1975) to bring about deep levels of processing. Subjects in this condition were instructed to rate the connotative meaning of each word presented on the dimension strong-weak. A rating sheet containing 30 seven-point rating scales with the word strong typed at one end and weak at the other was provided. In the instructions, the word "daffodil" was given as an example of a word which would likely be rated at the weak end of the scale, while "horse" was given as an example of a word connoting strong meaning. For subjects in the incidental condition, no mention was made of the subsequent memory tests for the list of words. Subjects in the intentional condition were instructed to learn the list of words in preparation for a subsequent condition.

Following a single presentation of the word list, all subjects were given a blank sheet of paper and instructed to write down, in any order, all the words they could remember from the presented list. This free-recall test was scored for the number of concrete, abstract, and total words correctly recalled. The recognition test immediately followed free recall. Subjects were 
Table 6. Means and standard deviations of word list recall and recognition scores for incidental and intentional groups.

\begin{tabular}{lcccc}
\hline & Intentional $(n=30)$ & $\frac{\text { Incidental }(n=32)}{\text { Mean }}$ & S.D. \\
\hline & Mean & S.D. & & \\
\hline $\begin{array}{c}\text { Concrete } \\
\text { Recal1 }\end{array}$ & 4.1 & 1.8 & 3.2 & 2.2 \\
$\begin{array}{c}\text { Abstract } \\
\text { Recal1 }\end{array}$ & 3.5 & 1.8 & 3.3 & 1.8 \\
$\begin{array}{c}\text { Total } \\
\text { Recal1 }\end{array}$ & 7.6 & 3.2 & 6.5 & 3.0 \\
$\begin{array}{c}\text { Concrete } \\
\text { Hits } \\
\text { Abstract } \\
\text { Hits }\end{array}$ & 9.2 & 2.6 & 11.5 & 2.1 \\
$\begin{array}{c}\text { Corrected } \\
\text { Hits }\end{array}$ & 7.5 & 2.4 & 9.6 & 1.8 \\
\hline
\end{tabular}

instructed to circle those words which they recognized as having been presented in the word list. The number of concrete and abstract words correctly identified (hits) was separately recorded; a total corrected recognition score was obtained by subtracting the number of "false alarms" (circled distractors) from the total number of hits.

\section{Results and Discussion}

The means and standard deviations of the various word-list retention measures for the two learning conditions are presented in Table 6 . In regard to the recall measures, unweightedmeans analysis of variance indicated no significant effects of word type (concrete vs. abstract), condition (intentional vs. incidental) or their interaction. However, analysis of recognition hits yielded a significant main effect for word type ( $F$ $(1,60)=42.8, p<.001)$, indicating a higher hit rate for concrete words and for learning condition $(F(1,60)=19.8, p<.001)$, with the incidental group outperforming the intentional subjects. The interaction was not significant. The incidental group also had a significantly higher total corrected recognition score $(t(60)=4.5 p<$
$.001)$ with the overall false-alarm rates not differing for the two groups (mean $=5.2$ for incidental and 5.6 for intentional). Thus, with respect to the effects of imageability and level of processing, results of the present study are in agreement with previous research.

While a comparison of group means on the individual difference measures indicated no significant differences between the incidental and intentional conditions, the pattern of correlations with the retention scores, presented in Table 7, did differ for the two groups. As can be seen, the predicted differential relationships between intentional and incidental learning and the $I L P$ scales emerged. Specifically, the Study Methods scale obtained significant correlations with recall only in the intentional condition, while in the incidental condition the SynthesisAnalysis and Elaborative Processing scales were the only scales significantly correlated with recall. None of the $I L P$ scales correlated with the recognition scores, with the exception of one significant relationship between Synthesis-Analysis and the total corrected recognition score in the incidental condition $(r=.44)$. This latter relationship is due to the fact that there was a sig- 


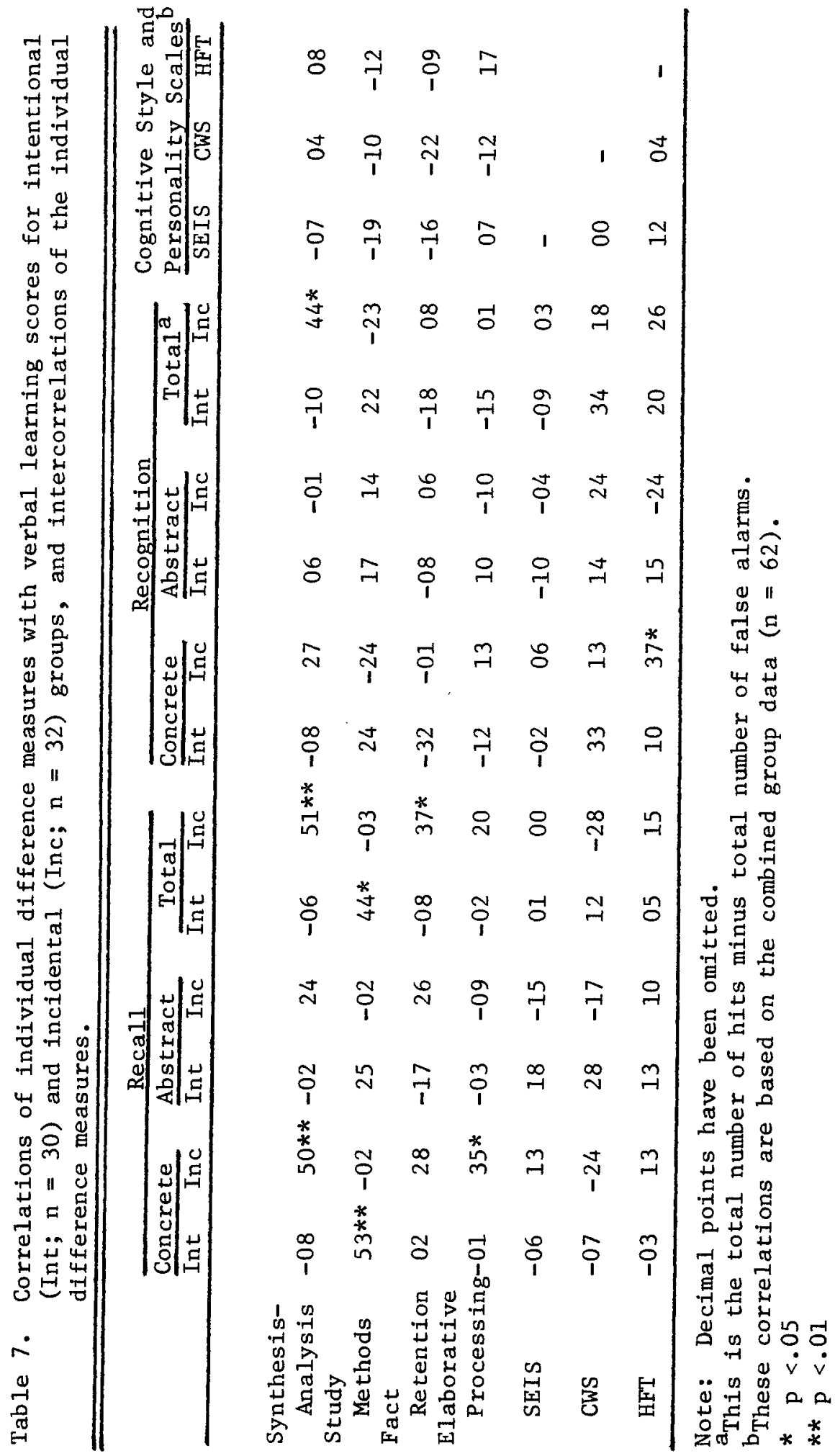


nificant negative correlation between SynthesisAnalysis and false-alarm making ( $r=-.35$ ). Thus, high scorers on the Synthesis-Analysis scale were not necessarily better in recognizing correct words, but they were better in their ability to reject incorrect words. The overall tendency for the $I L P$ to relate to recall measures but not recognition measures seems to indicate that the $I L P$ scales are tapping search and retrieval processes more than storage processes. Note also that abstract word retention is not related to any of the scales, while concrete word measures do show some relationships. This supports the notion that concrete words are more amenable to the encoding and processing strategies utilized by individuals in such a learning task (Paivio, 1976) and measured by the scales of the $I L P$.

Contrary to expectation, the Fact Retention scale showed a stronger relationship to recall in the incidental condition than in the intentional. This outcome suggests that the Fact Retention scale might not be so much a measure of the tendency to actively memorize facts as it is a measure of general memory for details. Of the three additional scales employed, only the $H F T$ obtained a significant correlation with any of the retention measures. We can think of no reasonable explanation for the $H F T$-concrete hits correlation in the incidental condition and the result is likely to be spurious.

The correlations of the ILP scales with the SEIS, CWS, and HFT are also given in Table 7 , as are the intercorrelations of the latter three scales. The independence of the $I L P$ as a measure of learning processes is evident. The three additional measures are also quite unrelated to each other. It is interesting to note that the correlation between Fact Retention and Category Width is in the expected direction, with narrow categorizers indicating better memory for details.

In general, then, the pattern of correlations between the $I L P$ scales and the verbal-learning measures supports the notion that instructions to learn elicit well-practiced study strategies which restrain the learner from engaging in in- formation-processing strategies and which lead to the same quality or better performance when there is no pressure to learn (i.e., in incidental learning). Such results provide valuable information both about the nature of the processes assessed by the $I L P$ as well as their function in the acquisition of knowledge.

\section{SUMMARY AND CONCLUSIONS}

Based on recent laboratory research in human learning and memory, an instrument was developed to assess individual differences in learning processes within the academic setting, utilizing behaviorally oriented statements. Using the factor analytic approach, the following four scales were obtained: Synthesis-Analysis, Study Methods, Fact Retention, and Elaborative Processing. These scales have acceptable levels of internal consistency and test-retest reliability. There were no sex differences on any of the scales. While future research will necessarily involve further explication of the meaning and utility of each learning-process scale, some basic interpretations are suggested by the available data.

The Synthesis-Analysis scale appears to assess the ability of students to glean organization from a unit of material as well as the ability to reorganize it. In addition to its relation to the organizational processes typically studied in the verbal- and prose-learning areas, the scale is also related to Bloom's (1956) three highest categories of cognitive activity (i.e., synthesis, analysis and evaluation). Although the label Synthesis-Analysis emphasizes only two of Bloom's (1956) high-level cognitive activities, it should be noted that the significant negative correlation between this scale and "false alarms" on the recognition test of Study 5 suggests that the scale also assesses the evaluation process, with high scorers seeming to evaluate the content of their memory more carefully before making choices on a recognition test.

The extent to which a student rigidly adheres to study techniques and behaviors which have 
traditionally been regarded as conducive to learning in academic settings is assessed by the Study Methods scale. A high scorer on this scale would likely be labeled a "good student" in the traditional sense. The finding from Study 5 that this scale related to performance only under intentional learning instructions implies that the study techniques assessed by the scale are applied only when the individual is specifically instructed to learn the material.

A student's ability to store or retain detailed factual information is assessed by the Fact Retention scale. Since Study 5 indicated a significant positive relationship between scores on the Fact Retention scale and recall in the incidental learning condition, the scale may be assessing a memory capacity which influences learning even in the absence of "studying" in the traditional sense. Although a similar relationship was not obtained under the incidental conditions of Study 4 , the difference between the conceptual lecture material used in that study and the verbal list used in Study 5 makes it difficult to interpret this discrepancy in findings at the present time.

Finally, the Elaborative Processing scale seems to assess the lengths to which a student will go in order to encode new information. The elaborative techniques assessed by the scale include interrelating new and old information, using visual imagery, rephrasing in one's own words, and thinking of practical applications. The Synthesis-Analysis and Elaborative Processing scales taken together appear to assess the tendency to take an active rather than a passive role in the processing of new information. Likewise, both scales seem to assess the habitual use of "deep" rather than "shallow" informationprocessing strategies (Craik \& Tulving, 1975), an assumption supported by the finding in Studies 4 and 5 that high scorers do well on incidentallearning tasks. Thus, as one would expect, the results of Study 3 show a positive correlation between these two scales, and Studies 4 and 5 indicate that the two scales tend to relate or not relate to performance as a pair.

However, there is some evidence regarding the differential validity of the Synthesis-Analysis and Elaborative Processing scales. On a proselearning task (intentional paradigm), the second author (Ribich, 1976) reported significant positive relationships between the Synthesis-Analysis scale and note-taking efficiency, objective examination performance, and free recall of idea units, while obtaining no relationships between those prose-learning variables and the Elaborative Processing scale. In addition, Ribich noted significant relationships between scores on the American College Testing Program $(A C T)$ college entrance exam and the $S y n$ thesis-Analysis and Fact Retention scales but not on the Elaborative Processing or Study Methods scales. Thus, although both the Synthesis-Analysis and Elaborative Processing scales deal with similar aspects of information processing, it is not likely that they are measuring precisely the same processes.

Study 5 of the present report indicated that the Study Methods scale was significantly related to performance only under intentional learning instructions, while Synthesis-Analysis, Fact Retention, and Elaborative Processing evidenced such a relationship under incidentallearning instructions. A similar pattern of results was obtained in Study 4; performance on an unexpected exam following a videotaped lecture was only related to the Synthesis-Analysis and Elaborative Processing scales. Such results are consistent with the findings of Craik and Tulvig (1975) who note that in verbal-learning studies, incidental learners will often perform as well as (or even better than) intentional learners if the instructions given to the incidental group encourage deep processing of the material. The implication is that the well-practiced study habits which are elicited when subjects are simply instructed to learn might, on occasion, displace more effective information-processing strategies such as those assessed by the $I L P$ 's Synthesis-Analysis and Elaborative Processing scales or those elicited by "deep processing" instructions in an incidental learning task. Taken as a whole, this analysis suggests that students (and teachers for that matter) are not always 
aware of which learning behaviors are most conducive to learning. As a matter of fact, some of the supposedly "effective study habits" which they employ may turn out to be less effective than simply listening to or reading the information in a thoughtful, elaborative manner. Tangential support for this analysis comes from Ribich's (1976) finding that $A C T$ scores show a significant positive relationship with scores on the Synthesis-Analysis scale but are not related to scores on the Study Methods scale.

McKeachie (1974) notes that very few innovative techniques produce clearly superior learning when studied in the context of empirical research. He also voices the opinion that more of these studies should permit the observation of attribute-treatment interactions. It is frequently the case that half of the studies concerned with an instructional technique report that it is effective and half report that it is not. In fact, most of these techniques are probably effective with certain students under certain conditions. For example, Duchastel and Merrill (1973) report that the widely acclaimed procedure of providing students with behavioral objectives sometimes aids learning and sometimes has no effect, but they suggest that some of the confusion would be eliminated if researchers attempted to relate the performance measures to the characteristics of the individuals within the subject sample. For example, they refer to one study (Etter, 1969) that obtained no main effect of behavioral objectives but did find that males with high socioeconomic status profited more than any other group from the availability of objectives. A major problem is that the attribute measures employed in such studies are either very gross (e.g., socioeconomic status) or else they consist of personality and cognitive-style measures which have not been specifically designed to assess learning processes. Since the $I L P$ was specifically designed for the latter purpose, future research will be aimed at determining whether any of the more publicized instructional techniques interact with $I L P$ scale scores. Furthermore, Glaser (1972) suggests that there is a need in the educational field for new meas- ures which deal with skills that are trainable and which are conceptualized in terms of processes. Since the Synthesis-Analysis and Elaborative Processing scales of the ILP seem to provide operational definitions of two "skills" of the type referred to by Glaser, the present authors will attempt to devise training procedures which will increase a student's ability to employ them to his/her advantage in the academic setting.

In addition, Underwood (1975) suggests that the validation of a theoretical learning process should begin by determining whether individuals differ reliably in the extent to which they demonstrate the process. The present instrument was designed to measure individual differences in the processes which served as guides while preparing items, but further research is required to determine whether the $I L P$ dimensions and the processes suggested by laboratory research do in fact correspond. For example, the theoretical organizational processes of clustering and subjective organization seem to be assessed by the Synthesis-Analysis scale, but further research is needed to determine whether highs scorers on this scale do, in fact, demonstrate more clustering and subjective organization as measured by standard laboratory techniques. Similar studies should be concerned with the relationship between encoding strategies (e.g., imagery usage) and the Elaborative Processing scale and between depth of processing and both the Synthesis-Analysis and Elaborative Processing scales.

\section{References}

Anderson, R. C., \& Kulhavy, R. W. Imagery and prose learning. Journal of Educational Psychology, 1972, 63, 242-243.

Bendig, A. W. The Pittsburgh scales of social extraversion-introversion and emotionality. The Journal of Psychology, 1962, 53, 199-209.

Berdie, R. F., \& Campbell, D. P. Measurement of interest. In D. K. Whitla (Ed.), Handbook of measurement and assessment in behavioral sciences. Reading, MA.: Addison-Wesley, 1968.

Biggs, J. B. Faculty patterns in study behavior. Australian Journal of Psychology, 1970, 22 , 161-174. 
Bloom, B. S. (Ed.). Taxonomy of educational objectives. Handbook: Cognitive domain. New York: David McKay, 1956.

Boersma, F. J. Test-retest reliability of the CF-1 Hidden Figures Test. Educational and Psychological Measurement, 1968, 28, 555-559.

Bousfield, A. K., \& Bousfield, W. A. Measurement of clustering and of constancies in repeated free recall. Psychological Reports, 1966, 19, 935-942.

Cattell, R. B. The scree test for the number of factors. Multivariate Behavioral Research, 1966, $I$. 245-276.

Cattell, R. B. How good is the modern questionnaire? General principles for evaluation. Journal of Personality Assessment, 1974, 38, 115-129.

Cowell, M. D., \& Entwistle, N. J. The relationship between personality, study attitudes, and academic performance in a technical college. British Journal of Educational Psychology, 1971, 41, 85-90.

Craik, F. I. M., \& Tulving, E. Depth of processing and retention of words in episodic memory. Journal of Experimental Psychology: General, 1975. 104, 268-294.

Cronbach, L. J. The two disciplines of scientific psychology. American Psychologist, 1957, 12 , $671-684$.

Cropley, A. J., \& Field, T. W. Achievement in science and intellectual style. Journal of Applied Psychology, 1969, 53, 132-135.

Duchastel, P. C., \& Merrill, P. F. The effects of behavioral objectives on learning: A review of empirical studies. Review of Educational Research. $1973,43,53-68$.

Earhard, M. Free recall transfer and individual differences in subjective organization. Journal of $E x$ perimental Psychology, 1974, 193, 1169-1174.

Etter, D. C. G. Adult learner characteristics and instructional objectives. Unpublished doctoral dissertation, University of California, 1969.

Eysenck, M. W. Individual differences in speed of retrieval from semantic memory. Journal of $R e$ search in Personality, 1974, 8, 307-323.

Eysenck, M. W. Extraversion, verbal learning, and memory. Psychological Bulletin, 1976, 83, 75-90.

Frase, L. T. Paragraph organization of written materials: The influence of conceptual clustering upon the level and organization of recall. Journal of Educational Psychology, 1969, 60, 394-401.

French, J. W., Ekstrom, R. B., \& Price, L. A. Manual for Kit of Reference Tests for Cognitive Factors. Princeton, N.J.: Educational Testig Service, 1963.

Gagné, R. M. Learning and individual differences. Columbus, OH: Charles E. Merrill Publishing Co., 1967.

Glaser, R. Individual and learning: The new aptitudes. Educational Research, 1972, 13, 5-13.
Goldman, R. D., \& Warren, R. Discriminant analysis of study strategies connected with college grade success in different major fields. Journal of Educational Measurement, 1973, 10. 39-47.

Kaiser, H. F. The varimax criterion for analytic rotation in factor analysis. Psychometrika, 1958, 23. 187-200.

McKeachie, W. J. Instructional psychology. Annual Review of Psychology, 1974, 25, 161-193.

Melton, A. W., \& Martin, E. (Eds.). Coding processes in human memory. Washington, DC: Winston \& Sons, 1972

Paivio, A., Imagery and verbal processes. New York: Holt, Rinehart and Winston, 1971.

Paivio, A. Imagery in recall and recognition. In $\mathrm{J}$. Brown (Ed.), Recall and Recognition, New York: John Wiley and Sons, 1976.

Paivio, A., \& Csapo, K. Picture superiority in free recall: Imagery or dual coding. Cognitive Psychology, 1973, 5, 176-206.

Paivio, A., Yuille, J. C., \& Madigan, S. Concreteness, imagery, and meaningfulness values for 925 nouns. Journal of Experimental Psychology Monograph Supplement, 1968, 76, No. 1, Part 2, $1-25$.

Pettigrew, T. F. The measurement and correlates of category width as a cognitive variable. Journal of Personality, 1958, 26, 532-544.

Plenderleith, M., \& Postman, L. Individual differences in intentional and incidental learning. British Journal of Psychology, 1957, 48, 241-248.

Ribich, F. Performance on word list and prose learning tasks as a function of learning style. Unpublished Master's thesis, Southern Illinois University, 1976.

Rorer, L. G., \& Goldberg, L. R. Acquiescence in the MMPI? Educational and Psychological Measurement, 1965, 25. 801-817.

Schultz, C. B., \& DiVesta, F. J. Effects of passage organization and note taking on the selection of clustering strategies and on recall of textual materials. Journal of Educational Psychology. $1972,63,244-252$.

Schwartz, S. Individual differences in cognition: Some relationships between personality and memory. Journal of Research in Personality. 1975 , 9. 217-225.

Tallmadge, G. K., \& Shearer, J. W. Relationships among learning styles, instructional methods, and the nature of learning experiences. Journal of Educational Psychology, 1969, 60, 222-230.

Tallmadge, G. K., \& Shearer, J. W. Interactive relationships among learner characteristics, types of learning, instructional methods and subject matter variables. Journal of Educational Psychology, $1971,62,31-38$. 
Thompson, C. P., Hamlin, V. J., \& Roenker, D. L. A comment on the role of clustering in free recall. Journal of Experimental Psychology, 1972, 94. 108-109.

Tulving, E., Subjective organization in free recall of "unrelated" words. Psychological Review, 1962, $69,344-354$.

Tulving, E. \& Donaldson, W. (Eds.). Organization of memory, New York: Academic Press, 1972.

Underwood, B. J. Individual differences as a crucible in theory construction. American Psychologist. $1975,30,128-134$.
Vaughan, D. S. The relative methodological soundness of several major personality factor analyses. Journal of Behavioral Science. 1973, 1, 305-313.

Wang, M. D., \& Stanley, J. C. Differential weighting: A review of methods in empirical studies. Review of Educational Research, 1970, 40, 663-705.

\section{Author's Address}

Ronald Ray Schmeck, Department of Psychology, Southern Illinois University, Carbondale, IL 62901 